\title{
The Same but Different: Making Meaning from Modified Texts with Cross-cultural Themes
}

\author{
Cynthia B. Leung \\ University of South Florida St. Petersburg \\ U. S. A. \\ Susan V. Bennett \\ University of South Florida St. Petersburg \\ U. S. A. \\ AnnMarie Alberton Gunn \\ University of South Florida St. Petersburg \\ U. S. A.
}

ABSTRACT: Reader response theory provides the framework for the present study that explored literary elements and cultural responses of fifth-grade students to two modified versions of a cross-cultural text, Homesick: My Own Story by Jean Fritz. One group of students read the first chapter of the book and another group read a modified basal reader version that had deleted cultural information. Group discussions of the texts were videotaped and transcribed. Through constant comparative analysis of field notes and transcripts, two themes emerged: (a) personal interest and connections to stories and (b) cultural implications and misinterpretations.

KEYWORDS: modified texts, reader response, text adaptations, cultural misunderstandings, cross-cultural texts

\author{
Literature Review \\ Theoretical Perspective \\ Methodology \\ Findings \\ Discussion and Implications \\ References \\ Author Contact
}

Reading materials for literacy instruction have often been modified to address students' needs at different stages of literacy development and different levels of maturity. Some texts may be modified to fit the complexity level appropriate for a particular grade level or reader characteristics. Quantitative aspects of text complexity, such as word frequency, sentence length, and text cohesion, can be measured through a number of computer programs. However, qualitative dimensions of text complexity, including text structure, language clarity, and different levels of meaning, as well as demands made on the reader's prior 
knowledge, cultural knowledge, and disciplinary knowledge, are more difficult to identify (National Governors Association, 2010). Goodman, Shannon, Freeman, and Murphy (1988) noted two major types of text adaptations: (a) to fit readability requirements and skill criteria set by publishers, and (b) to fit acceptable standards of content, language, and values.

Publishers set length requirements that may place a constraint on the length of modified texts. Large segments of an original text may be deleted in order to reduce total word count (Liebling, 1986, 1989). In addition, publishers of graded readers have policies of "information control" related to the selection and modification of stories for their readers (Claridge, 2012, p. 111). Through interviews of editors of graded readers for English Language Learners (ELLs) published in the United Kingdom, Claridge found that information control included "aiming to make texts more acceptable to all markets by situating topics in relatively 'culturally neutral' contexts" (p. 116). Editors wanted to be politically correct in the inclusion of topics covered in the readers, but they avoided sensitive topics, such as religion and homosexuality. Cambridge Readers did have stories about sensitive topics, but the stories tended to be more "culture-free" than in the other readers evaluated (Claridge, 2012, p. 111). Hill (2008) also found that contemporary stories in graded readers had "simpler plots and thinner characterisation, especially at the higher levels" (p. 200).

When texts are modified to meet publishers' requirements for educational materials, essential elements of the original narrative, including events and characterization, may be changed or deleted. Cultural elements and social issues dealt with in the original text may be deleted or simplified, resulting in a different interpretation. Few studies have explored the meaning-making processes of students who read modified texts that delete or change cultural information. The present study addressed this gap in reader response research by comparing how fifth-grade American students made meaning from two versions of a cross-cultural text, Homesick: My Own Story, Jean Fritz's memoir about her childhood in China. One group of students read the first chapter of the original book, and the other group read a basal reader version of that chapter. Although language in the basal reader text was not simplified, this version was shorter than the original and deleted important information about Chinese culture. Of particular interest in the study were the meaning-making processes of the group that read the basal reader adaptation with the deleted cultural information.

\section{Literature Review}

While a goal of literacy instruction is to help students make meaning from a variety of text types, the vocabulary, text structure, and content of some texts may be challenging to some students. Texts at lower levels of complexity may be introduced first as a scaffold to lead students to the successful comprehension of more complex texts. When the focus of instruction is on word meaning and skill development, text adaptations may be characterized by "synthetic" or controlled 
language. However, simplification of texts to improve readability may actually increase the complexity of the work. Language cues important to the construction of meaning may have been deleted, and this could influence the reader's interpretation of the text (Davison, 1984). In addition, many children may prefer original versions of literature to simplified adaptations. Studies by Goodman (1986) and by Green and Olsen (1988) found children often preferred original stories to versions that had been revised following readability guidelines. Formulaic writing may destroy elements of style that make original works more attractive and enjoyable for children to read.

\section{Modified Texts for English Language Learners}

Reading materials modified for English language learners primarily use simplification or elaboration to improve comprehension (Kim \& Snow, 2009). Simplification of texts for ELLs involves using less challenging vocabulary and syntax, while elaboration involves "increasing redundancy and enhancing explicitness" through clarification and repetition (p. 131). Findings of studies on reading comprehension of ELLs using modified texts are inconsistent. Different types of modification have been found helpful depending on the proficiency level and background knowledge of learners and the type of comprehension studied (Brown, 1987; Lotherington-Woloczyn, 1993; Oh, 2001). While simplifying vocabulary and syntax may motivate ELLs to read more in English and may help learners "extract surface factual information" (Kim \& Snow, 2009, p. 131), choppy sentences and limited vocabulary and syntax may result in less coherence and cohesion, making it more difficult to infer appropriate meanings. Furthermore, the content may also be simplified when language is simplified (p. 133).

Both simplified and elaborated texts may benefit literal comprehension and allow learners to answer factual questions related to content, but elaborative texts appear to be more effective in promoting higher levels of understanding (Yano, Long, \& Ross, 1994). However, it is important to consider that any type of text modification can result in non-authentic texts, and unmodified sentences may be longer and more complex than those in adapted texts. Nonetheless, advanced ELLs should be exposed to authentic texts, so they can learn to make meaning from texts they will encounter in different contexts. Kim and Snow (2009) concluded that "modified text may be appropriate to help achieve certain specific short-term goals, such as learning specific content, but at some cost to the longterm advantages for language learning and comprehension skills" (p. 141). Systematic instruction in reading comprehension strategies may help students engage with texts effectively without the need for modified texts (p. 142).

Simplifying or eliminating cultural elements and social issues from texts for ELLs may result in different interpretations from those intended by the author. For example, when high school English as a Second Language (ESL) students in New Zealand read a modified version of The Cay (Taylor, 1994; retold by Strange, 1997), they did not identify racism and prejudice as the main themes of the novel 
(Marianne, 2007). A comparative analysis of two versions of the text, the modified and the original version, found that the modified version had excised the racist and prejudiced language of an 11-year-old Caucasian boy from Virginia towards Black West Indians. After being ship-wrecked on an island with a Black West Indian sailor, the boy experienced "inner conflicts between parentally received prejudices and his own emerging experiences" with the sailor (p. 64). Readers of the modified text could not see the boy's negative perceptions of a person of color become more positive as the two characters interacted with each other. The deletion of evidence in the story related to themes of racism and prejudice made it difficult for the students to interpret or understand a text about these themes.

\section{Making Meaning from Modified Narratives}

In modified texts, character development may be compromised, and descriptions that do not relate to key events may be deleted. In some instances, events that support the author's intended theme may be eliminated if not considered key events. Bruce (1984) found that interpersonal and internal conflict, inside view where characters' thoughts and purposes are revealed to the reader, and rhetorical structure were weakened in text adaptations. He argued that these aspects of text complexity contribute to the cohesiveness and clarity of narratives. After analyzing and comparing adapted texts with original texts, Green (1984) concluded that adapted texts seemed to focus more on presenting events than on developing characterization and motivation. Sentences not affecting action tended to be deleted, so some texts were reduced to an "unrelated sequence of events" (p. 184).

Comparing an adaptation of Judy Blume's Freckle Juice with the original novel, Liebling (1989) found that the adapted text had passages deleted that contained important information related to interpersonal conflict and character goals and beliefs. She concluded that such deletions make it more difficult for children to understand characters and the motivation for story events. The deletion of subtle cues important to the understanding of character motivation can lead to an interpretation of an adapted story that differs from the original. An adaptation, then, is not the same story as its original version since readers will construct different stories from the two texts. Liebling (1989) also argued that readers' personal experiences influence their interpretation of texts. In adapted stories where important information is deleted, children must use their personal knowledge of peer and family relationships to draw inferences regarding plausible character motivation. If a story is about a situation or character type a child has never encountered before, the child may have difficulty making inferences and constructing meaning from a revised text where subtle cues are omitted.

Golden (1989) drew on the theoretical framework of reading as a constructive process to explain the reader's relationship with excerpted texts. To create meaning from texts, readers respond to textual cues provided by the author and draw on their prior knowledge and experiences. Information from the text is 
combined into patterns, such as plot, character, and narrator. When these patterns or perspectives are integrated, they become the gestalt of the text. In adapted texts where authors' cues are altered or deleted, readers may have difficulty making sense of the story, or they may construct different perspectives from the adaptation than from the original version. In another type of modified text where readers are only provided an excerpt or segment of an original text, as when a single chapter of a novel is included in an anthology, readers will not be able to integrate textual perspectives to achieve a gestalt because they have not been provided information along the continuum of the original work.

\section{Theoretical Perspective}

This study is situated theoretically in reader response criticism. Rosenblatt $(1938 / 1976,1994)$ introduced the idea that the process of making meaning from a text involves the interplay of factors related to the reader, the text, and the social context in which the text is experienced. The reader's role in meaning making is active, bringing to a text his/her personality traits, memories, moods, and preoccupations. "The reader infuses intellectual and emotional meanings into the pattern of verbal symbols, and those symbols channel his thoughts and feelings (1938/1976, p. 25). Rosenblatt distinguished between two types of reading: efferent reading and aesthetic reading. Efferent reading focuses on gaining new information, answering questions, and solving problems, while aesthetic reading evokes images, feelings, and ideas and can make connections to one's lived experiences. Many literacy texts do not have a single interpretation. Since readers construct their own meaning, there are a range of responses to a text. Furthermore, the same text may have different meanings and values when approached by a reader at different times or under different circumstances.

Other reader response theorists after Rosenblatt held to the importance of this transaction between reader and text while focusing on textual, experiential, psychological, social, or cultural aspects of the process of making meaning (Beach, 1993; Leung, 2003). Participants in this study took an aesthetic approach to the reading of the excerpted texts with a focus on their personal and experiential transactions with the text, as well as their responses to literacy elements of the texts. The focus of the analysis was on transactions among characteristics of the texts, individual interpretations by readers, and the social context of a small group discussing the meaning of the texts. Fifth-grade students responded to the versions of Homesick (Fritz, 1982) in small groups of four students as Galda (1982) had organized participants in her study of spectator stance with fifth-grade readers.

\section{Methodology}

This qualitative reader response study collected eight fifth-grade students' reactions to either an original cross-cultural story or an adapted version of the 
story. This section describes the participants, the texts used for the study, data collection procedures, and data analysis.

\section{Participants}

All eight fifth graders attending an alternative school, affiliated with a U. S. university's college of education, participated in this study. The students, who were all European American, were randomly assigned to either Group 1 or Group 2. Group 1, which consisted of three boys and one girl, read a basal reader adaptation, and Group 2, which consisted of four boys, read the first chapter of the original book. Their teacher considered all the students to be reading at grade level.

\section{The Texts}

Two texts were compared in this study: (a) the first chapter of Jean Fritz's (1982) memoir Homesick: My Own Story and (b) an adapted version of the first chapter of Homesick that appeared in a basal reader (Fritz, 1987). Jean, the main character who is of European American heritage, tells about growing up in China. Her father was the director of the YMCA in Hankow, China, during her childhood. As a child of foreign-born parents, Jean participated in the colonial system, viewing Chinese culture through her own experiences. She saw herself as a displaced American who would one day live in America. In the first chapter of Homesick, Jean covers a three-day period during her fifth grade year. She attended a British school and shares an experience where lan, a classmate, bullied her for refusing to sing "God Save the King." In other scenes in that chapter, Jean interacts with household servants, skips school the following day to explore Hankow and the waterfront, and resolves her conflict with lan after she returns to school.

In the adapted text, segments of the original chapter were deleted. As a result of removing passages, some characters and events were eliminated in the basal selection. In addition, segments of text that depicted life in Hankow and customs of the Chinese were omitted, resulting in a de-emphasis of the crosscultural dimensions of the original text. Illustrations by Margot Tomes and photographs of Jean Fritz and her family and friends were replaced in the basal text by illustrations created specifically for the adaptation. To minimize differences in interpretation that might result from different physical formats of the two texts, all students received photocopies of the excerpted selections to read. The photocopied versions of Homesick also would prevent students from knowing they were reading excerpts from a longer text.

Group 1 read a photocopy of the basal selection of Homesick (Fritz, 1987), which contained six illustrations: (a) a small illustration of a Chinese junk; (b) a one-page illustration of Jean holding her foot while standing next to her classmate 
lan who had just stomped on it; (c) a half-page illustration of a girl as viewed through two moon gates; (d) a three-quarters-of-a-page illustration of Jean embroidering while sitting next to a Chinese woman; (e) an illustration spread on the top half of two pages of a scene along a shore with mountains in the distance, on the left with the ribs of a boat being built and on the right with Jean handing fruit to a Chinese child; and (f) a final one-page illustration of Jean singing while standing in her classroom with a British flag on the wall in the background. In all illustrations, Jean wore glasses and a school uniform-a pleated skirt, white shirt with a collar, and a sweatshirt with the school name across the front. The printed text consisted of $113 / 4$ pages.

Group 2 read a photocopy of the first chapter of Homesick: My Own Story (Fritz, 1982). Only one illustration in the original chapter was included in this text, which showed Lin Nai Nai, Jean's amah (nursemaid), sitting in a wicker chair embroidering. No illustrations of Jean were in the version of Homesick given to Group 2. The printed text contained $181 / 2$ pages, making this version approximately seven pages longer than the basal version.

\section{Procedures}

Table 1. Questions Guiding Students' Responses

General Purpose Did you like the story?

What did you like about it?

What didn't you like about it?

Characterization Did you like Jean?

What did you like about her?

Are you the same kind of person as Jean?

Do you know anyone like Jean?

Were there any other people in the story who were interesting to you?

Events Were there parts of the story you didn't understand?

Which parts did you like and why?

What was your favorite part of the story?

Cultural Aspects Did you ever read anything about Chinese culture before?

Do you know anything about Chinese or about Chinese culture?

Did this story give you an idea of how people used to live in China?

Genre Did you ever read this kind of story before?

What kind of story do you think this is? 
Group 1 independently read the adapted version of Homesick silently in their classroom while Group 2 worked on other class assignments. After reading the modified text, Group 1 moved to an empty classroom where the first author, who will be referred to as the researcher, asked the students questions about the text and encouraged them to share their thoughts about what they had just read. While Group 1 discussed the reading, Group 2 independently read Chapter 1 of the original chapter from Homesick. Following the silent reading of the text, Group 2 discussed their reading selection with the researcher. After they read their version of Homesick, each group was immediately interviewed, and the discussion sessions were audio and video recorded. Students' names are pseudonyms.

The researcher guided both discussion sessions with a predetermined set of questions (see Table 1). These questions focused on narrative elements of the text and cultural information revealed by the story. Students were asked to share their emotional responses to the work, to relate the text to their own experiences, and to discuss literary aspects of the selection. After the discussions, students were given a copy of the book Homesick (Fritz, 1982) to read the book in its entirety.

\section{Data Analysis}

We chose constant comparison as the qualitative method to analyze the data since we wanted to understand the experiences of the fifth-grade students as they read and interacted with two different versions of a story. This method was used to analyze the researcher's field notes and transcripts of the video interviews in order to find developing themes (Strauss \& Corbin, 1990; Leech \& Onwuegbuzie, 2007). All three authors read and reread the data. The data from the two discussions were compared to each other as theories were formed and enhanced. First, we classified the data into chunks and then allocated labels to those chunks as they were compared to one another, further formulating theories. Next, themes were identified across data. Two of the authors then met to compare themes and establish inter-rater reliability.

\section{Findings}

Through participation in a small group discussion, the students and researcher created meaning from the two texts. The "social, spoken language communicative context" (Liebling, 1989) of the discussion groups made it possible for participants to collaboratively interpret the stories and to offer personal reactions to the texts and experiences of the story characters. Although the researcher was primarily concerned with narrative elements of the texts, the discussions were intended to be an environment of sharing ideas. The researcher used predetermined questions only as a guide to elicit student responses about characterization, action, motivation, theme, and cultural differences. She kept the 
discussion moving forward but stepped back from a position of group leader whenever the students maintained the discussion on their own. Most importantly, the researcher did not present herself as an authority, nor did she interpret the texts for the students. Her knowledge of the texts and familiarity with Chinese culture, however, allowed her to respond to student comments as a fellow participant in the process of creating meaning from the excerpted texts.

\section{Personal Interest and Connections to Stories}

Group 1 did not particularly like the adapted version of Homesick. When asked if they liked the story, all students politely answered, "Yeah," Um hum." Further probing led to more honest responses, such as Summer's comment, "It was all right but...um it didn't hold my interest." Students suggested they preferred reading mysteries or books about famous sports figures. Questions about narrative elements of the text usually received brief replies. However, the group was eager to talk about personal experiences. The researcher attempted to use the students' past knowledge and personal experiences to draw them into a discussion of the text since the text itself did not hold much interest for these particular students.

It was difficult for the researcher to elicit a discussion of characterization. When asked, "Did you like Jean?" and "Did you like her as a person?" Ed replied, "I never met her." The researcher continued with the idea of imagining Jean as a living person, rather than a story character and asked, "Do you think you would have liked her if she were in your class?" This question brought Don, who had barely spoken up to this point, into the discussion. He couldn't hide his excitement to contribute.

Don: $\quad$ Ed would have probably torn her... had her torn apart already.

Researcher: Ed would have torn her apart? Why?

Don: $\quad$ She already had lost one arm. Ed would have taken the other arm with him. (The researcher then drew Ed into the scene imagined by Don.)

Researcher: Uh no! Are you like lan? Is Ed like lan?

Ed: What! Me, mean? I'm not mean. I'm nice, I think. Am I nice?

Don: We heard that. (Everybody laughed.)

By placing themselves into the setting, Don and Ed were able to understand the characters' actions, the meanness and cruelty of the bully lan in his taking advantage of Jean and causing her physical pain.

When the group focused on the most important or best part of the story, their discussion showed that events and characters are inseparable narrative elements. Burke (1969) and Golden (1990) have argued that it is difficult to distinguish act from agent since a character's behavior is related to his or her personality traits. For the students in Group 1, the act-agent ratio proved important 
in their interpretations of the characters' actions. Ed and Don most liked the scene in the schoolyard at recess.

Ed: $\quad$ When the guy came out and stepped on her foot because he didn't um, she didn't sing the ah...What's it called? "God save the King," whatever.

Don: I like when ah she got her arm twisted.

Later in the discussion, Don added he also liked when lan stepped on Jean's foot. Ryan liked the end of the story when Jean sang "My Country Tis of Thee" while the rest of her class in the British school sang "God Save the King." Summer nonverbally agreed the best part of the book chapter was when lan bullied Jean.

Ed articulated why he thought it was important to have that scene in the story: "You have to have some action in there, some excitement." He and Don continued to imagine Jean as a real person. Ed placed himself into Jean's shoes and thought of how he would react if lan had stepped on his foot.

Ed: I think she should have HIT him for everything she had. She had her chance.

Don: $\quad$ Yeah, Yeah, that's gonna be real good, when she was holding one foot and trying to hit with the other hand.

Ed: $\quad$ Well, he was stepping on her foot at the time.

Students in Group 2 responded to the unabridged chapter of Homesick on different levels. Responses appeared to be directed more towards the text than to personal experiences, as with Group 1. Jack thought that the story was "weird" and his comments focused on individual words that were used in ways unfamiliar to him. He was especially intrigued by the words "bloody" and "junk." Jack had remembered the context in which "bloody" was used, when lan had told Jean, "If you don't sing, you'll be bloody sorry." When asked if he knew what "bloody" meant, Jack replied it meant "you'll be dead...you'll be sorry...it's an expression." The word "bloody" had been omitted from the adapted selection, most likely because it was considered inappropriate language for children. But for Jack this word acted as an entrance into the text. Jack also was fascinated by the word "junk," a type of Chinese boat. He made puns with the word: "All boats are junk," "My room is junk." Throughout the discussion, Jack continued to make puns on these and other words.

Jack admitted he did not understand the story well and that "it was hard to pay attention to it." He added, "I just think the story didn't catch on...it didn't make me want to read it... there wasn't enough action as you're going through the story." Richard thought the reading selection "was boring and too long," but he did like the scene where Jean discovered the wooden frame of a junk at the Mud Flats. Gene and David both liked the story. Gene's favorite scene was the final scene at school when Jean sang "My Country Tis of Thee" instead of "God Save the King." David liked best when Jean skipped school. David's enjoyment of the text, in fact, was the result of an error of interpretation; he thought that Jean was a boy. Because 
the reading selection had been photocopied, he had not seen the cover of the paperback edition of Homesick (1982) where Jean was shown sitting on the dock. The only illustration in Chapter 1 of the book was the drawing of Lin Nai Nai, Jean's amah. However, the basal adaptation presented four illustrations of Jean. David was further confused because he knew Jean could be both a girl's and boy's name. A classmate, one of the other participants in Group 2, was named Gene.

David closely identified with Jean because, like Jean, he did not like going to school: "I like it when he didn't go to school. I think that's my role model." She was interesting to David because she had "revolted," refusing to do what was socially acceptable when she felt personally wronged. To David, Jean's behavior appeared to be consistent with what a boy would have done in the same situation. When asked why he thought Jean was a boy, David explained:

I don't know because I guess that guy was trying to beat him up and stuff and like ...this is weird if it was a girl. And also because at the end where the police officer says little miss, it was like why is he calling him little miss? It was like what's going on?

The gender of the main character also posed problems for some of the boys in Group 1. Ed admitted since the story was about a girl, he did not like it much. When the researcher asked him if he liked stories about girls, he shook his head to indicate "no." It is important to note, however, that even though Ed may not have liked the story, he still was able to imagine himself in Jean's situation, projecting himself into the role of a female character.

Since the adapted text eliminated some of the characters that appeared in the original chapter, Group 1's discussion of characterization was limited and centered mostly on Jean and lan. Summer was the only student in Group 1 who thought Lin Nai Nai was important to the story because Jean "wanted to see her so badly...because the way Jean ran up to her room to see her or whatever." Unfortunately, there was a deleted passage in the adapted text that provided a brief autobiography of Lin Nai Nai and explained that an amah was a servant who took care of children. Although Lin Nai Nai was referred to as an amah, none of the readers of the adapted text knew who or what an amah was because of deleted material. Furthermore, the basal illustration of Lin Nai Nai and Jean embroidering gives the impression that the amah was much younger than she actually was.

\section{Cultural Implications and Misinterpretations}

Summer misinterpreted Lin Nai Nai's relationship to Jean's family and thought the amah was a close friend rather than a servant. In the way Lin Nai Nai was portrayed, the adapted version unnecessarily distorted a character who played a major role in Jean's childhood. Students in Group 2 who read the original version did not have this misconception. They understood that Lin Nai Nai was a servant and also realized that the events in Jean's memoir took place in an earlier historical time. 
David: $\quad$ This is like...this is in the 1980s or something.

Researcher: I think this is in...around 1925 to 1927.

David: $\quad$ Oh, I thought so.

Researcher: Why did it seem like a different time to you?

David: Because they were still doing the same old cultures like they had servants and stuff.

Researcher: Yeah, they had servants.

David: Because now China is pretty much a free country. All the counties are pretty much free.

Before reading versions of Jean Fritz's memoir, both groups had only read about Chinese culture through folktales. The reading of Homesick provided an opportunity for these fifth-grade students to become more familiar with the way of life in China before the time of the uprisings organized by Mao Tse-tung in the mid1920s. In Chapter 1 of her memoir, Fritz described the city of Hankow at that time: the foreign concessions or sections of the city that were reserved for the French, Russians, and Germans; the Bund where the Customs House and the promenade were located; the signs forbidding Chinese, with the exception of coolies, from entering the Bund; the sights and sounds of the Chinese part of the city; the beggars; the huts along the river at the Mud Flats; and the broken glass on top of walls around personal residences. The basal adaptation of Homesick deleted these references to Chinese culture during that time period. The entire scene where Jean wandered through the streets of Hankow before visiting the Mud Flats was omitted. Also deleted was the scene in the kitchen where the cook, Yang Sze$\mathrm{Fu}$, made a snack for Jean, and Jean recalled the butter pagodas he created for dinner parties at her home. The elimination of all this cultural information resulted in an adapted text that distorted the relationship between the Chinese and their foreign guests. Most importantly, because of omitted passages, an inaccurate depiction of Chinese culture during that time period was presented.

In order to determine the effect of these deletions of the cultural context, the researcher asked both groups of students what they had learned about Chinese culture from reading the selections. Students in Group 1 replied they did not learn much about Chinese culture. Ryan explained all Chinese are real smart.

Ryan: How come all Chinese people are smart?

Researcher: Did you get that idea from the story or you just have that idea?

Ryan: I just had that idea.

(Don and Ed joined in the discussion of how smart Chinese are, and they shared personal experiences of interacting with Chinese.)

Don: It's like...it's like they're all smart. 
(Ed used his index fingers to make slanted eyes and talked privately with Ryan.)

Ryan: $\quad$ Cause they're always ...

Don: $\quad$ They think they have a computer in their head or something.

Ed: $\quad$ Yeah, I rode on this bus with Chinese people and I hear them talk like about math and all and they go right into their language.

Researcher: Are you confused when you hear them speak different languages?

Ed: Yeah.

Don: Yeah, trying to understand their language is really hard...especially when they come up to you like on a bus and they start talking to you and you're there like...

Ed: $\quad$ Yeah, yeah.

Ryan: $\quad$ You know like the things they make...like cars...Futaba...and Tiama

Don: It's really a pain when you're sitting there trying to read and they come up to you and like...

Ryan: $\quad$ OK...

Ed: $\quad$ How do you use this radio here?

Don, Ryan, and Ed held to their prior cultural and racial stereotypes of Chinese and their aptitude in mathematics. Also, they confused Chinese culture with Japanese, thinking the Chinese produced such cars as "Futaba" and "Tiama" (Toyota and Honda?). These students did not appear to expand their knowledge of Chinese culture by reading the adapted text, nor did they become more sensitive to cultural issues. Students in Group 2, on the other hand, pointed out specific things they had learned about Chinese culture by reading Chapter 1 of Homesick. They mentioned learning that Chinese called their boats "junks," that they used to have servants, that they had gods like sea gods, and that little boys didn't wear pants. They talked about the kinds of food Jean ate, oranges and egg sandwiches, and wondered if she ever ate Chinese food. They also wondered what it would be like to live in another country and eat the food of that culture. Jack said he would not eat sushi if he lived in Japan; David said he would like to try it. Students in Group 2 also discussed how Jean had taken advantage of Lin Nai Nai's lack of skill in speaking English to trick her into thinking the phrase "sewing machine" was a greeting in English. Both versions of the story did contain the section about the Chinese boy who had a pigtail in his hair so the gods would think he was a girl. Both groups recalled this detail about Chinese culture.

Since the discussion styles varied somewhat with the two groups, the topics of discussion for each group were examined to find points in common. Comparing topics discussed by both groups, it was found that the students who read the 
original version of the first chapter of Homesick discussed a wider range of events and details related to characterization than the group that read the adapted version.

Group 1 primarily discussed events in three scenes: the initial scene with Jean and lan where lan bullied Jean on the playground, the scene at the Mud flats where Jean shared her orange with a Chinese boy, and the concluding scene where Jean sang "My Country 'Tis of Thee," while her classmates sang, "God Save the King." It is interesting to note that these three scenes were also depicted in illustrations in the adapted text but not in the original memoir. Comments by students in Group 1 show the illustrations were an important factor in their understanding of the text. Students mentioned details from the illustrations that were not written in the text. For example, Don said Jean was holding one foot after lan stepped on it. In addition, Ryan and Don both were intrigued by the curl on top of the head of the Chinese boy at the Mud Flats. Ryan used his fingers to make the shape of a curl on top of his head similar to the curl in the illustration, and Don commented about the boy: "I like the way he did his hair. It was like half fish and half boy...eerick eerick." Don then picked up a section of hair from the top of his head and made it into a large curl.

\section{Discussion and Implications}

Students who read the original version included more story events in their discussion of the text and also referred to attitudes and motives of characters. They discussed cultural differences and characters that were eliminated from the adapted text. Overall, their discussion was more focused on the text while students of Group 1 who read the adaptation focused more on personal experiences that seemed unrelated to the actual events of the story. While participating in the discussion of Homesick with the group reading the basal adaptation, the researcher felt she had to prod the discussion along. Students preferred to discuss folktales they had previously read or wanted to talk about their experiences with Asian people. The discussion with the group reading the first chapter of Homesick moved forward through comments made by group members. Students, as well as the researcher, asked questions. Cross-cultural aspects of Jean's life interested the students, and some imagined themselves in a similar situation. While the adapted version was interpreted more as a school story or a story about patriotism, the original story was seen in the complexity of its cultural context.

Although it is difficult to completely understand the process a reader goes through while making sense of a story, the discussions elicited from the two groups of fifth-grade students offer indications of the topics that were of interest to them. Through the discussions, the students were able to create meaning in a social context and to modify and extend their original interpretations of the texts. Deleting references to specific aspects of Chinese culture in the mid-1920s appears to have distorted the interpretations students derived from the adapted text. Deleting scenes and events from the original chapter led students to read the adapted text 
as a school story, rather than a story of adapting to life in a different culture. Since personality traits are revealed in part by a character's actions in a particular setting (Rimmon-Kenan, 2002), adapted texts that delete aspects of the character's physical and human environment present the reader with a different story than what the author had originally intended to present.

The findings of this research demonstrate the importance of using unabridged texts for students to make meaning fully, especially when it comes to cultural understandings and misunderstandings. When using basal readers because of curriculum requirements, teachers should compare the abridged version of narratives in the reader to the original text so they can guide discussions and help students to acquire information that was removed, especially if their students are not familiar with the cultural setting of the text. Understanding that a range of cultural positions influences students' meaning-making from texts compels us to select texts for literacy instruction that are not misleading in the ways cultural information is presented. "Students depend on us to locate, when appropriate, the cultural access points that will enable a story to resonate and become meaningful for them" (Brooks \& Browne, 2012, p. 83).

If teachers are limited to basal readers for reading instruction, they can compile text sets to accompany the stories they find in their basal readers (Mathis, 2010). By referring to a variety of texts that relate to different cultural concepts presented in the story, teachers can provide different perspectives on the same concept and build students' cultural knowledge of the content of the basal text. Teachers can also use nonfiction materials such as maps, primary source photos, and multimodal video links to extend vocabulary and provide cultural backgrounds. Other resources can include picture books that show different perspectives on the same culture. This type of instruction is especially important for ELLs because they may need additional experiences with related resources to broaden their vocabulary knowledge and to develop strong comprehension skills. These opportunities are greatly enhanced when students have access to a variety of texts and are engaged deeply with these texts (Cummins, 2011).

\section{References}

Beach, R. H. (1993). Emerging perspectives on planning and change processes. Journal of School Leadership, 3, 646-665.

Brooks, W., \& Browne, S. (2012). Towards a culturally situated reader response theory. Children's Literature in Education, 43, 74-85. doi:10.1007/s10583011-9154-z3

Brown, R. (1987). A comparison of the comprehensibility of modified and unmodified reading materials for ESL. University of Hawaii Working Papers in ESL, 6, 49-79. 
Bruce, G. (1984). A new point of view on children's literature. In J. Osborn \& R. J. Tierney (Eds.), Learning to read in American schools: Basal readers and content texts (pp. 153-174). Hillsdale, NJ: Erlbaum.

Burke, K. (1969). A grammar of motives. Berkeley, CA: University of California Press.

Cummins, J. (2011). Literacy engagement. The Reading Teacher, 65, 142-146. doi:10.1002/TRTR.01022

Claridge, G. (2012). Graded readers: How the publishers make the grade. Reading in a Foreign Language, 24, 106-119.

Davison, A. (1984). Readability formulas and comprehension. In G. Duffy, L. R. Roehler, \& J. Masor (Eds.), Comprehension and instruction: Perspectives and suggestions (pp. 128-143). New York, NY: Longman.

Fritz, J. (1982). Homesick: My own story. New York, NY: Dell.

Fritz, J. (1987). Homesick. In M. Early et al. (Eds.), Portraits (pp. 306-321). New York, NY: Harcourt Brace Jovanovich.

Galda, L. (1982). Assuming the spectator stance: An examination of the responses of three young readers. Research in the Teaching of English, 16, 1-20.

Golden, J. M. (1989, November-December). Text factors in modified texts: The case of the excerpted text. Paper presented at the National Reading Conference, Austin, Texas.

Golden, J. M. (1990). The narrative symbol in childhood literature: Explorations in the construction of text. New York, NY: Mouton de Gruyter.

Goodman, K. S. (1986). What's whole in whole language? Portsmouth, NH: Heinemann.

Goodman, K. S., Shannon, P., Freeman, Y. S., \& Murphy, S. (1988). Report card on basal readers. Katonah, NY: Richard C. Owen.

Green, G. (1984). On the appropriateness of adaptation in primary-level basal readers: Reactions to remarks by Bertram Bruce. In R. C. Anderson, J. Osborn, \& R. J. Tierney (Eds.), Learning to read in American schools: Basal readers and content texts (pp. 175-191). Hillsdale, NJ: Erlbaum.

Green, G., \& Olsen, M. S. (1988). Preferences for and comprehension of original and readability-adapted materials. In A. Davison \& G. Green (Eds.), Linguistic complexity and text comprehension (pp. 115-140). Hillsdale, NJ: Erlbaum.

Hill, D. R. (2008). Graded readers in English. ELT Journal, 62(2), 184-204. doi:10.1093/elt/ccn006

Kim, Y.-K., \& Snow, C. E. (2009). Text modification: Enhancing English language learners' reading comprehension. In E. H. Hiebert \& M. Sailors (Eds.), Finding the right texts: What works for beginning and struggling readers (pp. 129-146). New York, NY: Guilford Press. 
Leech, N. L., \& Onwuegbuzie, A. J. (2007). An array of qualitative data analysis tools: A call for qualitative data analysis triangulation. School Psychology Quarterly, 22, 557-584.

Leung, C. (2003). Bicultural perspectives and reader response: Four American readers respond to Jean Fritz's Homesick. Canadian Modern Language Review, 60(1), 27-54.

Liebling, C. R. (1986). Inside view and character plans in original stories and their basal reader adaptations. (Technical Report No. 379). Urbana-Champaign, IL: University of Illinois, Center for the Study of Reading.

Liebling, C. R. (1989). Inside view and character plans in an original story and its basal adaptation. Theory into Practice, 28(2), 88-97.

Lotherington-Woloczyn, H. (1993). Do simplified texts simplify language comprehension for ESL Learners? Eric Document Reproduction Service No. ED371583

Mathis, J. B. (2010). Picture book text sets: A novel approach to understanding theme. The Clearing House: A Journal of Education Strategies, 75(3), 127131. doi: $10.1080 / 00098650209599251$

Marianne. (2007). A comparative analysis of racism in the original and modified texts of The Cay. Reading in a Foreign Language, 19, 56-68.

National Governors Association Center for Best Practices \& Council of Chief State School Officers. (2010). Supplemental information for Appendix A of the Common Core State Standards for English Language Arts and Literacy: New research on text complexity. Retrieved from http://db.readinglions.net/ commoncore/downloads/supp_appendix_a_textcomplexity.pdf

Oh, S. (2001). Two types of input modification and EFL reading comprehension: Simplification versus elaboration. TESOL Quarterly, 35, 69-96.

Rimmon-Kenan, S. (2002). Narrative fiction: Contemporary poetics. New York, NY: Routledge.

Rosenblatt, L. M. (1938/1976). Literature as exploration. New York, NY: Noble \& Noble.

Rosenblatt, L. M. (1994). The reader, the text, the poem: The transactional theory of the literary work. Carbondale, IL: Southern Illinois University Press.

Strange, D. (1997). The cay. London, United Kingdom: Penguin Books.

Strauss, A., \& Corbin, J. (1990). Basics of qualitative research: Grounded theory procedures and techniques. Newbury Park, CA: Sage Publications.

Taylor, T. (1994). The cay. London, United Kingdom: Penguin Group Puffin Books.

Yano, Y., Long, M. H., \& Ross, S. (1994). The effect of simplified and elaborated texts on foreign language reading comprehension. Language Learning, 44, 189-219. doi:0.1111/j.1467-1770.1994.tb01100.x 


\section{Author Contact}

Cynthia B. Leung, cleung@mail.usf.edu

College of Education, University of South Florida, $140-7^{\text {th }}$ Ave. S, St. Petersburg, FL 33701

Susan V. Bennett, sbennet3@usfsp.edu

College of Education, University of South Florida, 140-7 th Ave. S, St. Petersburg, FL 33701

AnnMarie Alberton Gunn, gunn@usfsp.edu

College of Education, University of South Florida, 140-7 ${ }^{\text {th }}$ Ave. S, St. Petersburg, FL 33701 